\section{Biomarkers for glaucoma: from the lab to the clinic}

\begin{abstract}
Glaucoma, a leading cause of irreversible blindness worldwide, is often not diagnosed until many years after disease onset. Early and objective diagnostic measures are yet missing. Besides the main risk factor, an elevated intraocular pressure (IOP), age, sex, and ethnicity are known to affect disease progression and severity. Furthermore, oxidative stress, elevated glutamate concentrations, and an autoimmune component are considered possible risk factors. We could identify several potential proteomic biomarkers in glaucoma and examine distinct changes in the glaucomatous human retina proteome. Using an
\end{abstract} experimental autoimmune glaucoma animal (EAG) model we could demonstrate an IOPindependent loss of retinal ganglion cells (RGC), which is accompanied by antibody depositions and increased levels of microglia. In a different animal model we showed that intermittent IOP elevations provoke neurodegeneration in the optic nerve and the retina and elicit changes of IgG autoantibody reactivities. The correlation between neuronal damage and changes in autoantibody reactivity suggests that autoantibody profiling could be a useful biomarker for glaucoma. In vivo studies on neuroretinal cells and porcine retinal explants demonstrated a protective effect of antibodies (eg, anti-GFAP) on RGC, which seems to be the result of reduced stress levels in the retina. We conclude that the absence of some autoantibodies in glaucoma patients reflects a loss of the protective potential of natural autoimmunity and may thus encourage neurodegenerative processes. Concluding, autoantibody profiles resemble useful biomarkers for diagnosis, progression and severity of glaucoma. Future longitudinal studies will help to improve early detection and enable better monitoring of disease progression. Eye (2017) 31, 225-231; doi:10.1038/eye.2016.300; published online 13 January 2017
N Von Thun Und Hohenstein-Blaul, S Kunst, $\mathrm{N}$ Pfeiffer and FH Grus

Introduction

The term glaucoma subsumes a group of optic neuropathies that share characteristic morphological changes within the retinal nerve fiber layer and the optic nerve head which are associated with a slow and progressive retinal ganglion cell (RGC) death and visual field loss. ${ }^{1}$ Glaucoma is the most common cause for irreversible blindness and the second leading cause of blindness worldwide. ${ }^{2}$ The most frequent glaucoma form in the Western world is the primary open-angle glaucoma (POAG). ${ }^{3,4}$ Although the risk for POAG rises with the elevation of intraocular pressure (IOP) and an elevated IOP is the most common known risk factor for glaucoma, most patients with ocular hypertension will not develop glaucoma. ${ }^{5}$ It is assumed that risk factors others than IOP are mainly involved in the onset of the condition, especially depicted in glaucoma patients with statistically normal pressure levels less than $21 \mathrm{~mm} \mathrm{Hg}$, the so called normal tension glaucoma (NTG). ${ }^{6}$ Beside age, sex, and ethnicity, ${ }^{7}$ events such as oxidative stress, ${ }^{8}$ systemic and ocular vascular factors, ${ }^{9}$ elevated glutamate concentration ${ }^{10}$ or nitric oxide levels, ${ }^{11}$ or an autoimmune component ${ }^{12,13}$ are considered possible risk factors. It is also likely that a combination of multiple risk factors increases the possibility of developing glaucoma and may influence its severity and other phenotypic characteristics. ${ }^{14}$ By now, elevated IOP is the only risk factor that can be treated, for example, with medications or glaucoma surgery. Control of IOP early in the disease process has been shown to delay or even arrest glaucoma progression and the resultant visual field loss. ${ }^{15,16}$

The diagnosis of glaucoma requires a detailed examination of optic disc structure and visual field, assessing both structure and function of the eye. Unfortunately, most potential screening tests have an estimated specificity of approximately $85 \%{ }^{17}$ resulting in an insufficient

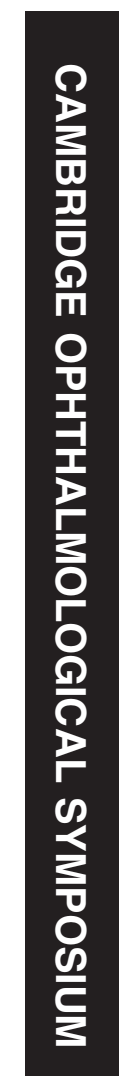

Experimental and

Translational

Ophthalmology,

Department of

Ophthalmology, University

Medical Center of the

Johannes Gutenberg

University Mainz, Mainz,

Germany

Correspondence:

FH Grus, Experimental and Translational

Ophthalmology,

Department of

Ophthalmology, University

Medical Center of the

Johannes Gutenberg

University Mainz,

Langenbeckstr. 1,

DE-55131 Mainz, Germany

Tel: +496131 173328 ;

Fax: +4961314970563.

E-mail: fgrus@eye-research.

org

Received: 26 October 2016 Accepted: 11 November 2016

Published online:

13 January 2017 
predictive power. Hence, most patients have suffered from glaucoma for over 10 years without knowing and as many as half of RGC and their axons can be lost before first pathological changes can be detected. ${ }^{18,19}$ Several epidemiological studies have shown that at least half of glaucoma patients remain undiagnosed in developed countries $^{20}$ and nine out of 10 worldwide. ${ }^{7}$ Especially the early diagnosis of the disease has an important role, since so far the threat of blindness can only be prevented by timely treatment through lowering the IOP. This underlines the strong demand for additional diagnostic options and disease or treatment monitoring, for example, by use of biomarkers. A biomarker is defined as a characteristic that is objectively measured and evaluated as an indicator of normal biological processes, pathogenic processes, or pharmacologic responses to a therapeutic

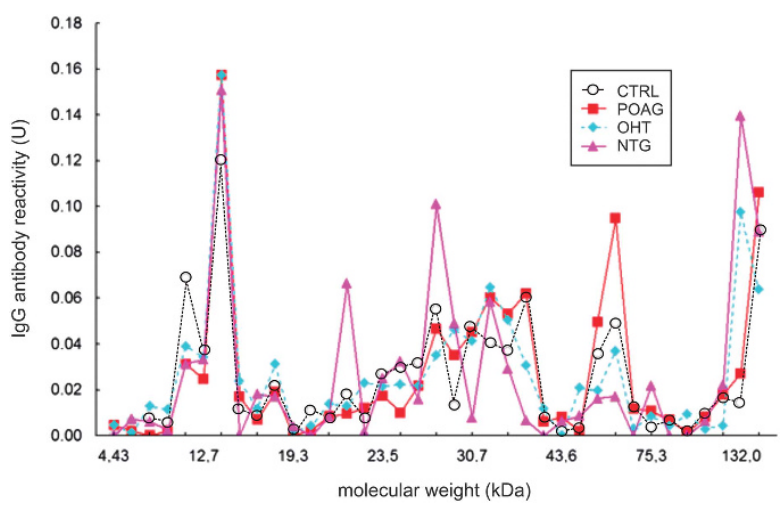

Figure 1 Antibody profiles against optic nerve antigens in different glaucoma groups. Antibody (IgG; immunoglobulin G) profiles against optic nerve antigens in two glaucoma groups (primary open-angle glaucoma (POAG) and normal tension glaucoma (NTG) in comparison to healthy controls (CTRL). The $x$ axis shows the molecular weight in kilodalton $(\mathrm{kDa})$ and the $y$ axis the IgG antibody reactivity (U). Complex IgG antibody profiles could be found in all groups. The antibody profiles of the glaucoma groups were significantly different from controls. ${ }^{28}$ (Courtesy of Molecular Vision) intervention, and has valuable applications in disease detection and monitoring of health status. ${ }^{21}$

\section{Identification of potential glaucoma biomarkers from clinical studies}

By now, several proteomic markers, for example, crystallins, ${ }^{22,23}$ heat shock protein 60 (HSP 60) and HSP 90, myotrophin, apolipoprotein B and apolipoprotein E, endothelial leukocyte adhesion molecule-1, myoblast determination protein 1 , myogenin, vasodilatorstimulated phosphoprotein, ankyrin-2 ${ }^{24}$ and transthyretin, ${ }^{25}$ just to mention a few, have been identified as potential biomarkers in POAG. In a recently published study ${ }^{26}$ we examined the human retina proteome of glaucoma patients by state-of-the-art mass spectrometry (MS) method. Distinct proteomic changes could be observed in $10 \%$ of proteins and support the involvement of three functional classes in glaucomatous processes: mitochondrial, stress and nucleus proteins, indicating an impairment of energy metabolism, stress response and gene expression alterations in the course of retinal neurodegenerative processes. Beside an increase of stress related proteins we also found a decrease of new glaucoma-related candidates, highlighting new molecular players ADP / ATP translocase 3 (ANT3), PC4 and SRFS1interacting protein 1 (DFS70) and methyl-CpG-binding protein 2 (MeCp2) associated with glaucoma. Moreover, these candidates could be validated by Accurate Inclusion Mass Screening and immunostaining, and supported for the RGC layer by laser capture microdissection, ${ }^{26}$ giving direction for future glaucoma research projects.

\section{Autoimmune involvement in glaucoma pathogenesis}

Several clinical and experimental studies point toward a possible autoimmune involvement in the pathogenesis of glaucoma. Disease-specific changes in complex expression levels of immunoglobulin G (IgG) autoantibodies against

Figure 2 Analysis in intermittent ocular hypertension model (iOHT). (a) The survival of RGC was analyzed as the number of Brn3apositive cells per mm retina in naso-temporal cross-sections of the eye in control animals (CTRL), animals that received unilateral intermittent ocular hypertension (iOHT), and animals with unilateral intermittent ocular hypertension which received B lymphocyte inhibitor Belimumab treatment (iOHT+Belimumab). A significant loss of RGC was observed in injured eyes of iOHT group and iOHT+B lymphocyte inhibitor Belimumab group, to hinder B lymphocyte activation, (both $P<0.01$, horizontal lines) compared with control eyes (black). Furthermore, a significant difference in damage was observed between fellow and injured eye of iOHT group $(P<0.05$. Significant values are indicated as follows: ${ }^{*} P<0.05,{ }^{* *} P<0.01$ ). (b and c) Quantification of different antigen reactivities The left side shows the immunoreactivities in relative intensities per group against glutathione S-transferase (b) and spectrin (c). Each triangle represents one animal, and the black line indicates the group median. Compared with the relative intensity of CTRL, iOHT was significantly upregulated $\left.{ }^{* *} P<0.01\right)$ for all investigated antigens. Compared with iOHT, all immunoreactivities of iOHT+Belimumab were significantly downregulated $\left.{ }^{\# \#} \mathrm{P}<0.01\right)$. Scatterplots of the number of optic nerve axons in a distinct area (no. of axons $\left./ 0.05 \mathrm{~mm} 2\right)$ against relative intensities of glutathione S-transferase (b) and spectrin (c), are shown on the right side. The gray fitting line shows the negative linear dependence between the number of axons per $0.05 \mathrm{~mm} 2$ and the relative intensities. Significant values are indicated as follows: ${ }^{* *} P<0.01$ compared with control group, ${ }^{\# \#} P<0.01$ compared with iOHT group. (Adapted from Gramlich $e t$ al ${ }^{43}$ ) 
ocular tissue could be detected in sera and aqueous humor of glaucoma patients suffering from different glaucoma forms: NTG, POAG, or patients with ocular hypertension (Figure 1). ${ }^{27-32}$ Furthermore, these autoantibody profiles are very stable and could be found in study populations from different continents. ${ }^{32}$ Especially worth mentioning is the fact that not only elevated antibody reactivities could be detected in the

a

RGC Analysis

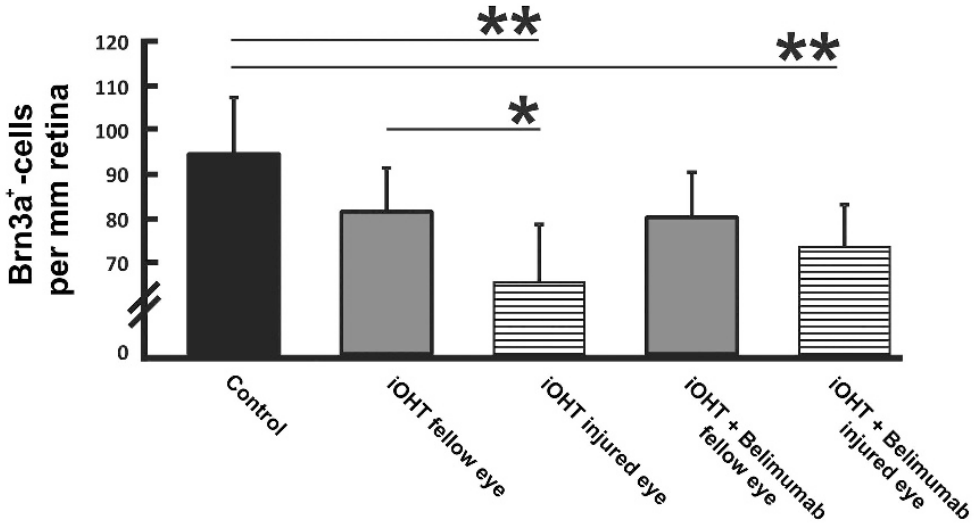

Immunoreactivities

Correlation analysis
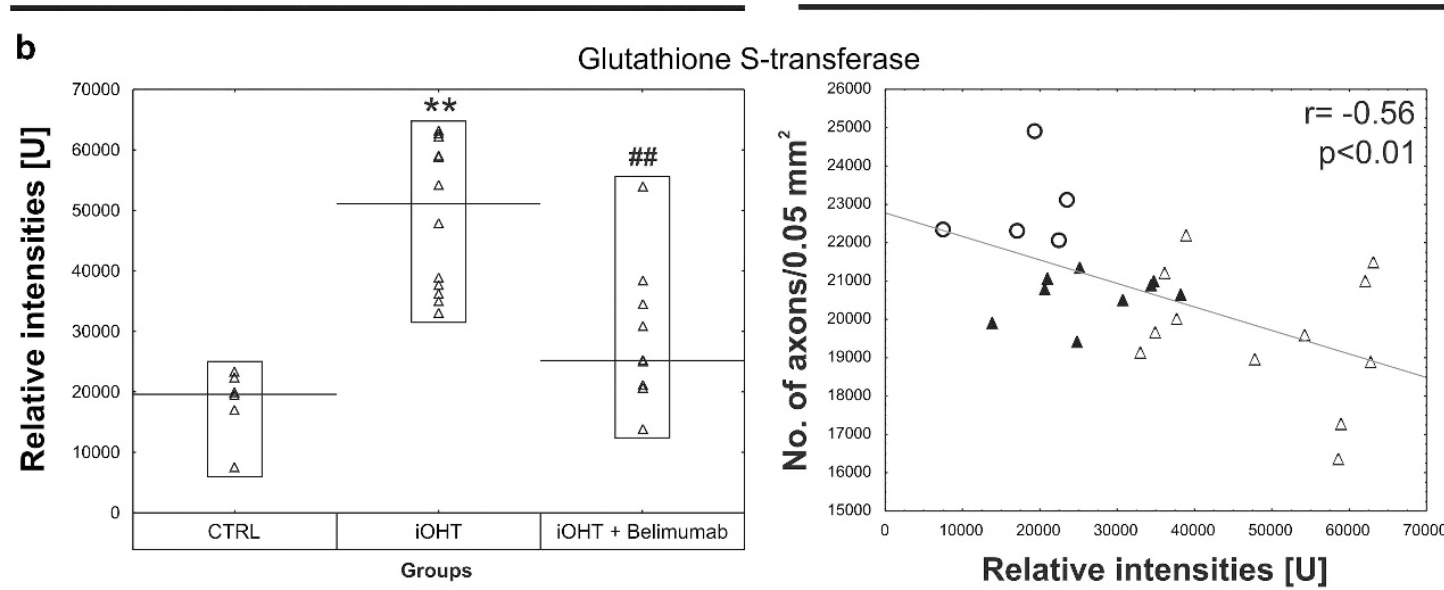

C

Spectrin
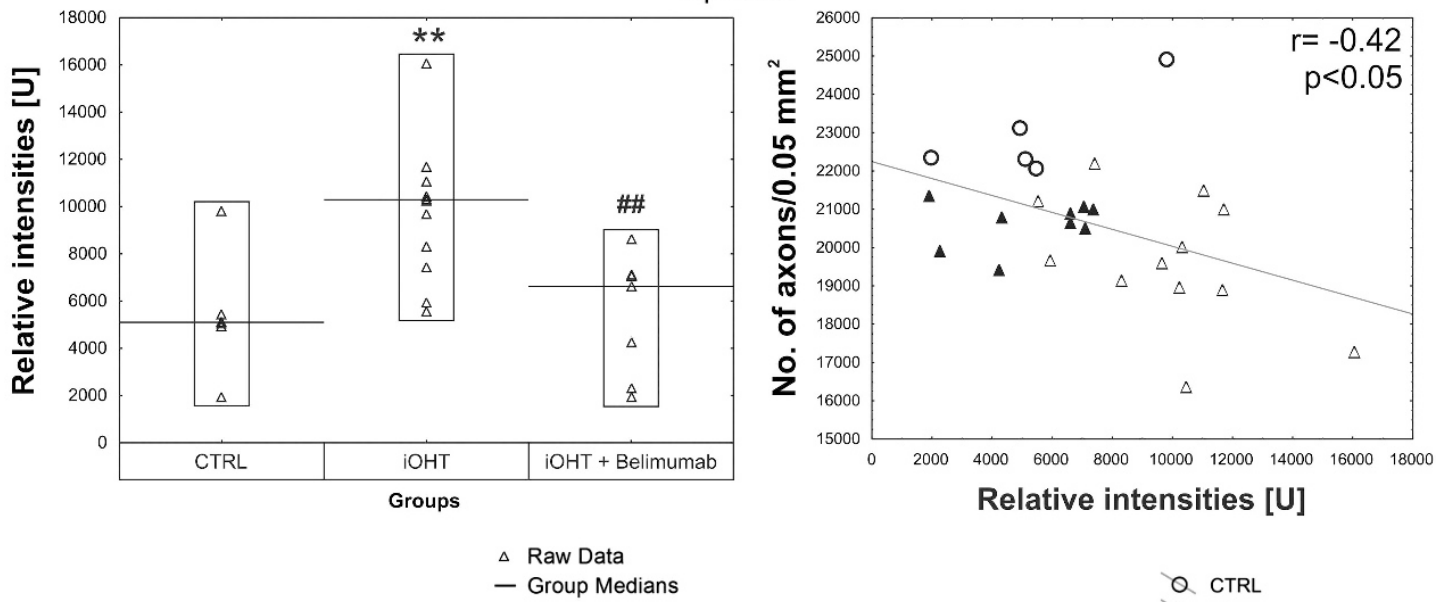

Q CTRL

$\triangle \mathrm{iOHT}$

\. $\mathrm{iOHT}+$ Belimumab 
glaucoma groups, but also a reduction of some antibody levels could be observed. Analyses in numerous glaucoma patients showed for example up-regulation of autoantibodies against alpha-fodrin, ${ }^{32} \mathrm{HSP}^{33}$ or myelin basic protein (MBP $)^{29}$ and downregulation of antibodies against $\alpha \mathrm{B}$-Crystallin or Vimentin, ${ }^{33}$ just to name a few.

To answer the question whether elevated antibody reactions can induce an autoaggressive RGC loss in animal models, an experimental autoimmune glaucoma animal (EAG) model has been developed. After being systemically immunized with biomarkers identified in clinical studies, the animals developed antibodies against the applied proteins, for example HSP60, ${ }^{34,35} \mathrm{HSP} 27^{35}$ or $\mathrm{MBP}^{36}$ resulting in glaucomatous damage with distinct retinal RGC loss. Subsequent EAG studies focused on the pathomechanism of immunizations with retinal and optic nerve associated antigens and showed that the IOPindependent RGC loss in EAG depends on the specificity of the antigen and leads to altered serum antibody patterns. ${ }^{37}$ Moreover, RGC loss after immunization with retinal antigens is accompanied by antibody depositions and increased levels of microglia. ${ }^{38-40}$

\section{IOP and immunity}

To further examine a possible link between elevated IOP and immune response we used a recently established intermittent ocular hypertension model, ${ }^{41,42}$ where a silicone loop is attached around the limbus of the eye to temporarily increase the IOP. After the manipulation, the IOP values return to baseline levels, which demonstrates that this model does not cause angle-closure glaucoma. ${ }^{43}$ We found evidence that intermittent IOP elevations are sufficient to provoke neurodegeneration in the optic nerve and the retina and elicit changes of IgG autoantibody reactivities. ${ }^{43}$ Unilateral intermittent IOP elevations led to a significant decrease of RGCs (Figure 2a) and their axons in the optic nerve, accompanied by bilateral microglia activation and IgG autoantibody depositions in the retina. Furthermore, a systemic immune response due to RGC loss in association with an increased IOP could be shown with a significant increase of serum IgG reactivities as well as IgG immunoreactivities against glutathione S-transferase (Figure $2 b$ ), spectrin (alpha-fodrin, respectively; Figure 2c), and transferrin. ${ }^{43}$ The additional immunomodulation using the B lymphocyte inhibitor Belimumab failed to ameliorate axonal and RGC survival and had very little effect on deactivation of microglia, and reduction of IgG autoantibody depositions despite lowering the total IgG serum concentration. However, the question remains whether such in vivo results are transferable to humans and how the circumstances in human glaucomatous patients are.
Nevertheless, the correlation between neuronal damage and changes in autoantibody reactivity suggests that autoantibody profiling could be useful as a biomarker for glaucoma. ${ }^{43}$

\section{Neuroprotective effects of antibodies on retinal explants}

Our previous in vitro studies showed that antibodies downregulated in glaucoma patients, for example, antibodies against glial fibrillary acidic protein (GFAP), 14-3-3 or gamma $(\gamma)$-synuclein, have protective effects on immortalized neuroretinal cells and increased their viability under stress conditions. ${ }^{44-46}$ This neuroprotective effect could be traced back to altered antiapoptotic protein expressions in the mitochondrial apoptosis pathway for gamma $(\gamma)$-synuclein antibody or anti-14-3-3, ${ }^{44,45}$ or to altered proteins of the actin cytoskeleton pathway for GFAP antibody. ${ }^{46}$

In subsequent experiments we used an adolescent retinal organ culture from pigs and incubated the retinal explants with different antibodies for $24 \mathrm{~h}$ (anti-GFAP, anti- $\gamma$-synuclein, and anti-myoglobin antibody as a control). In accordance with previous results, immunohistochemical analysis revealed a protective effect of anti- $\gamma$-synuclein and anti-GFAP antibodies on RGC survival (Figure 3) and demonstrated the uptake of $\gamma$-synuclein antibodies, as well as the binding of GFAP antibodies to the cell membrane of Müller cells. ${ }^{47}$ Furthermore, mass spectrometric results showed

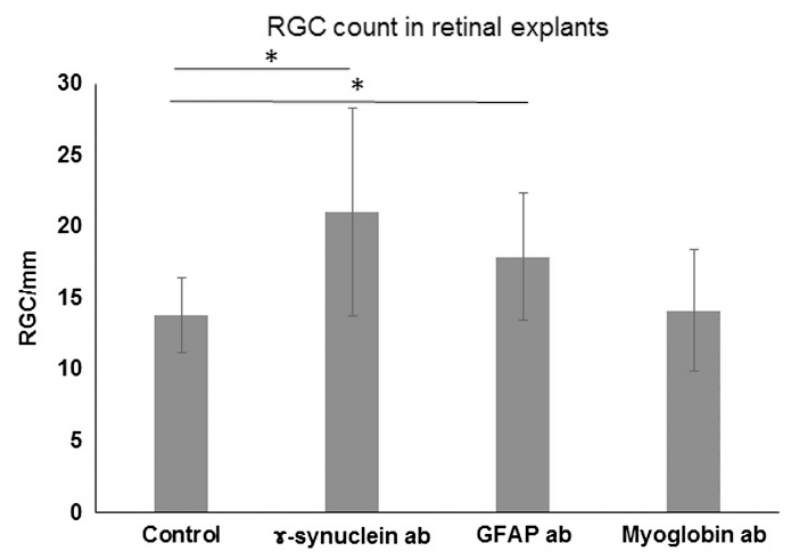

Figure 3 Effect of antibodies on the number of RGC in retinal explants from adolescent pigs. Retinal explants were cultivated either with control medium without additional antibodies (ab) (control) or with additional $\gamma$-synuclein antibodies or glial fibrillary acidic protein (GFAP) antibodies for $24 \mathrm{~h}$, or with anti-myoglobin antibodies, serving as an isotype-matched control antibody (ex vivo $27 \mathrm{~h}$ ). The Quantification of RGC/mm: revealed significantly increased RGC numbers in both the retinae incubated with GFAP antibodies as well as retinae incubated with $\gamma$-synuclein antibodies. ${ }^{*} P<0.05 ;{ }^{* *} P<0.01$ (error bars are SD; Adapted from Bell et al ${ }^{47}$ ) 
increased levels of glutamine synthetase in antibodytreated retinal explants. Glutamine synthetase is expressed exclusively in Müller cells and serves as a specific Müller cell marker. Müller cells are essential for RGC survival and have an important role in the recycling of neurotransmitters, homeostasis of the extracellular environment, removal of metabolic end products, as well as the supply with neurotrophic and antioxidant factors. ${ }^{48}$ The strong Müller cell involvement was found associated with reduced endoplasmic reticulum stress response, and a redistribution of glutamine synthetase localization in direction of the end feet of the Müller cells towards the inner retinal layer. These findings suggest that anti-GFAP and anti- $\gamma$-synuclein antibodies have a protective effect on RGC which seems to be the result of reduced stress levels in the retina. ${ }^{47}$ Possibly the absence or the loss of some autoantibodies in glaucoma patients (eg, anti-GFAP) reflects a loss of natural protective autoimmunity, thus encouraging neurodegenerative processes and making the RGC more vulnerable for stress factors. ${ }^{12}$

\section{Human glaucoma and autoimmunity}

Beside the consistent antibody profile in sera (Figure 1), aqueous humor and tears of glaucoma patients, ${ }^{27-33}$ we found evidence that autoantibodies are accumulated in the retinae of glaucoma patients and that the local immune homeostasis might be affected. ${ }^{49}$ More detailed, the IgG autoantibody deposits were accompanied by IgGpositive plasma cells (Figure 4) and occurred in proinflammatory conditions with increased levels of tumor necrosis factor- $\alpha$, interleukin- 6 and interleukin- 8 , which seems to be maintained locally by immune-competent cells like microglia. ${ }^{49}$ We suggest that microglia activation might provide the increased levels of tumor necrosis factor- $\alpha$ and interleukin- 8 in glaucomatous retina after activation by autoantibody depositions, maintain antibody-dependent cell-mediated cytotoxicity and regulate the pro-inflammatory homeostasis along with the recruitment of plasma cells. ${ }^{49}$ These findings comply with results from EAG where immunization led to an antigen specific, complex systemic immune response, which included the development of autoreactive antibodies against retinal and optic nerve epitopes with an increasing and time-dependent severity. ${ }^{37}$ The loss of RGCs in EGA model is also accompanied by IgG autoantibody deposits on cells in the RGC layer and often found in co-localization with activated microglia cells. ${ }^{38,39}$

\section{Improvement of glaucoma detection}

Despite of these results, it is still unclear whether the changes found in autoantibodies are pathogenic or merely a consequence of glaucomatous optic neuropathy. ${ }^{12}$

However, the distinct changes in antibody profiles could be used as biomarkers for the detection of glaucoma. And indeed, using a targeted antigen microarray we were able to differentiate sera of glaucoma patients with POAG from non-glaucomatous controls based on antibody profiles with a sensitivity and specificity of $>93 \%$ (Figure 5). ${ }^{50}$ This represents an enormous diagnostic precision when compared to established screening tests with an estimated specificity of $\sim 85 \% .{ }^{17}$ Furthermore, the correlation between damage and changes in the autoantibody reactivity found in the intermittent ocular hypertension model suggests that autoantibody profiling could also be useful as biomarkers for progression and severity of the disease. ${ }^{43}$ To further answer this question longitudinal studies are required that allow monitoring of glaucoma progression and permit the staging of the disease in correlation with antibody patterns. The analysis of longitudinal antibody profiles could also be useful to
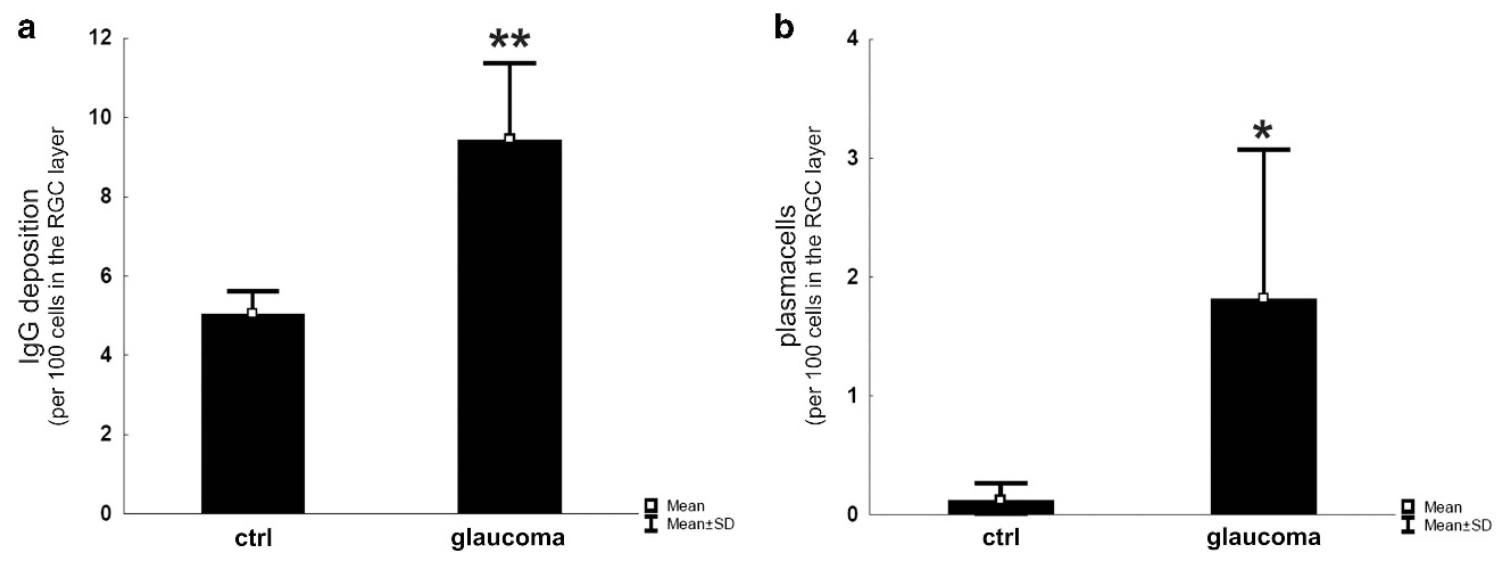

Figure 4 Quantification of IgG depositions and plasma cells in cross-sections of human glaucomatous and healthy retina. (a) The number of IgG deposits in relation to the number of remaining cells is significantly increased. (b) Based on morphological features, plasma cells were only detectable in the glaucomatous group. ${ }^{*} P=0.05 ;{ }^{* *} P=0.01$. (Adapted from Gramlich $e t a l^{49}$ ) 


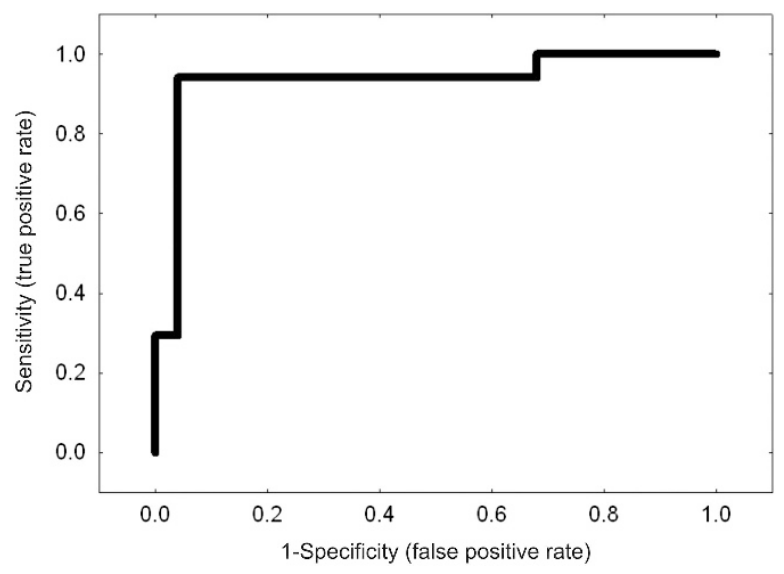

Figure 5 Sensitivity and specificity of autoantibody patterns for diagnosis. Receiver operating characteristic for comparison of autoantibody reactivities in serum samples of primary openangle glaucoma patients (POAG; $N=20$ ) and non-glaucomatous controls $(N=13)$ using specific antigen microarrays in combination with an artificial neural network (X-axis: 1-specificity, $\mathrm{Y}$ axis: sensitivity, $R=0.93$ ). The sensitivity and specificity for a discrimination of prospective glaucoma and control subjects was $93 \%$. (Reprinted from Boehm et $a l^{50}$ with permission from Elsevier).

detect glaucoma at an early stage before clinical signs appear.

In the future, a quick and easy to handle immunological test based on antibody responses could be used for diagnosis and screening purposes. Additionally, the altered antibody reactions could possibly offer new immunological targets for innovative treatment options

\section{Conflict of interest}

The authors declare no conflict of interest.

\section{Acknowledgements}

We are grateful to our collaborators that have contributed to the various studies in the Laboratory of Experimental and Translational Ophthalmology over the years. This research was supported in part by research grants from DFG (Deutsche Forschungsgemeinschaft, research funding organization in Germany); MAIFOR university Mainz, Forschungsschwerpunkt Translationale Neurowissenschaften (FTN, university Mainz), Stiftung Rheinland- Pfalz für Innovation (research funding organization in Germany) and Deutsche Ophthalmologische Gesellschaft (German Ophthalmic Society).

\section{References}

1 Tuulonen A, Airaksinen PJ, Erola E, Forsman E, Friberg K, Kaila $\mathrm{M}$ et al. The Finnish evidence-based guideline for openangle glaucoma. Acta Ophthalmol Scand 2003; 81(1): 3-18.
2 Quigley HA. Number of people with glaucoma worldwide. Br J Ophthalmol 1996; 80(5): 389-393.

3 Leske MC, Connell AM, Schachat AP, Hyman L. The Barbados Eye Study. Prevalence of open angle glaucoma. Arch Ophthalmol 1994; 112(6): 821-829.

4 Rudnicka AR, Mt-Isa S, Owen CG, Cook DG, Ashby D. Variations in primary open-angle glaucoma prevalence by age, gender, and race: a Bayesian meta-analysis. Invest Ophthalmol Vis Sci 2006; 47(10): 4254-4261.

5 Friedman DS, Wilson MR, Liebmann JM, Fechtner RD, Weinreb RN. An evidence-based assessment of risk factors for the progression of ocular hypertension and glaucoma. Am J Ophthalmol 2004; 138(3 Suppl): S19-S31.

6 Wilson MR. The myth of '21'. J Glaucoma 1997; 6(2): 75-77.

7 Quigley HA, Broman AT. The number of people with glaucoma worldwide in 2010 and 2020. Br J Ophthalmol 2006; 90(3): 262-267.

8 Tezel G, Yang X, Luo C, Kain AD, Powell DW, Kuehn MH et al. Oxidative stress and the regulation of complement activation in human glaucoma. Invest Ophthalmol Vis Sci 2010; 51(10): 5071-5082.

9 Yanagi M, Kawasaki R, Wang JJ, Wong TY, Crowston J, Kiuchi Y. Vascular risk factors in glaucoma: a review. Clin Experiment Ophthalmol 2011; 39(3): 252-258.

10 Dreyer EB, Zurakowski D, Schumer RA, Podos SM, Lipton SA. Elevated glutamate levels in the vitreous body of humans and monkeys with glaucoma. Arch Ophthalmol 1996; 114(3): 299-305.

11 Neufeld AH. Nitric oxide: a potential mediator of retinal ganglion cell damage in glaucoma. Surv Ophthalmol 1999; 43(Suppl 1): S129-S135.

12 Bell K, Gramlich OW, Von Thun Und Hohenstein-Blaul N, Beck S, Funke S, Wilding C et al. Does autoimmunity play a part in the pathogenesis of glaucoma? Prog Retin Eye Res 2013; 36: 199-216.

13 Wax MB. The case for autoimmunity in glaucoma. Exp Eye Res 2011; 93(2): 187-190.

14 Bhattacharya SK, Lee RK, Grus FH. Molecular biomarkers in glaucoma. Invest Ophthalmol Vis Sci 2013; 54(1): 121-131.

15 Leske MC, Heijl A, Hussein M, Bengtsson B, Hyman L, Komaroff E. Factors for glaucoma progression and the effect of treatment: the early manifest glaucoma trial. Arch Ophthalmol 2003; 121(1): 48-56.

16 Heijl A, Leske MC, Bengtsson B, Hyman L, Hussein M. Reduction of intraocular pressure and glaucoma progression: results from the Early Manifest Glaucoma Trial. Arch Ophthalmol 2002; 120(10): 1268-1279.

17 Burr JM, Mowatt G, Hernandez R, Siddiqui MA, Cook J, Lourenco $\mathrm{T}$ et al. The clinical effectiveness and cost-effectiveness of screening for open angle glaucoma: a systematic review and economic evaluation. Health Technol Assess 2007; 11(41)iii-iv, ix-x 1-190.

18 Quigley HA, Katz J, Derick RJ, Gilbert D, Sommer A. An evaluation of optic disc and nerve fiber layer examinations in monitoring progression of early glaucoma damage. Ophthalmology 1992; 99(1): 19-28.

19 Quigley HA, Dunkelberger GR, Green WR. Retinal ganglion cell atrophy correlated with automated perimetry in human eyes with glaucoma. Am J Ophthalmol 1989; 107(5): 453-464.

20 Burr JM, Campbell MK, Campbell SE, Francis JJ, Greene A, Hernandez R et al. Developing the clinical components of a complex intervention for a glaucoma screening trial: a mixed methods study. BMC Med Res Methodol 2011; 11: 54. 
21 Biomarkers Definitions Working Group. Biomarkers and surrogate endpoints: preferred definitions and conceptual framework. Clin Pharmacol Ther 2001; 69(3): 89-95.

22 Thanos S, Bohm MR, Meyer zu Horste M, Prokosch-Willing V, Hennig M, Bauer D et al. Role of crystallins in ocular neuroprotection and axonal regeneration. Prog Retin Eye Res 2014; 42: 145-161.

23 Lutjen-Drecoll E, May CA, Polansky JR, Johnson DH, Bloemendal H, Nguyen TD. Localization of the stress proteins alpha B-crystallin and trabecular meshwork inducible glucocorticoid response protein in normal and glaucomatous trabecular meshwork. Invest Ophthalmol Vis Sci 1998; 39(3): 517-525.

24 Sacca SC, Centofanti M, Izzotti A. New proteins as vascular biomarkers in primary open angle glaucomatous aqueous humor. Invest Ophthalmol Vis Sci 2012; 53(7): 4242-4253.

25 Grus FH, Joachim SC, Sandmann S, Thiel U, Bruns K, Lackner KJ et al. Transthyretin and complex protein pattern in aqueous humor of patients with primary open-angle glaucoma. Mol Vis 2008; 14: 1437-1445.

26 Funke S, Perumal N, Beck S, Gabel-Scheurich S, Schmelter C, Teister J et al. Glaucoma related Proteomic Alterations in Human Retina Samples. Sci Rep 2016; 6: 29759.

27 Joachim SC, Grus FH, Pfeiffer N. Analysis of autoantibody repertoires in sera of patients with glaucoma. Eur J Ophthalmol 2003; 13(9-10): 752-758.

28 Grus FH, Joachim SC, Hoffmann EM, Pfeiffer N. Complex autoantibody repertoires in patients with glaucoma. Mol Vis 2004; 10: 132-137.

29 Joachim SC, Reichelt J, Berneiser S, Pfeiffer N, Grus FH. Sera of glaucoma patients show autoantibodies against myelin basic protein and complex autoantibody profiles against human optic nerve antigens. Graefes Arch Clin Exp Ophthalmol 2008; 246(4): 573-580.

30 Joachim SC, Pfeiffer N, Grus FH. Autoantibodies in patients with glaucoma: a comparison of $\operatorname{IgG}$ serum antibodies against retinal, optic nerve, and optic nerve head antigens. Graefes Arch Clin Exp Ophthalmol 2005; 243(8): 817-823.

31 Joachim SC, Wuenschig D, Pfeiffer N, Grus FH. IgG antibody patterns in aqueous humor of patients with primary open angle glaucoma and pseudoexfoliation glaucoma. Mol Vis 2007; 13: 1573-1579.

32 Grus FH, Joachim SC, Bruns K, Lackner KJ, Pfeiffer N, Wax MB. Serum autoantibodies to alpha-fodrin are present in glaucoma patients from Germany and the United States. Invest Ophthalmol Vis Sci 2006; 47(3): 968-976.

33 Joachim SC, Bruns K, Lackner K, Pfeiffer N, Grus FH. Antibodies to alphaB-Crystallin, Vimentin, and Heat Shock Protein 70 in Aqueous Humor of patients with Normal Tension Glaucoma and IgG Antibody Patterns Against Retinal Antigen in Aqueous Humor. Curr Eye Res 2007; 32: 501-509.

34 Joachim SC, Wax MB, Seidel P, Pfeiffer N, Grus FH. Enhanced characterization of serum autoantibody reactivity following HSP 60 immunization in a rat model of experimental autoimmune glaucoma. Curr Eye Res 2010; 35(10): 900-908.

35 Joachim SC, Grus FH, Kraft D, White-Farrar K, Barnes G, Barbeck $\mathrm{M}$ et al. Complex antibody profile changes in an experimental autoimmune glaucoma animal model. Invest Ophthalmol Vis Sci 2009; 50(10): 4734-4742.

36 Gramlich OW, Joachim SC, Gottschling PF, Laspas P, Cuny CS, Pfeiffer $\mathrm{N}$ et al. Ophthalmopathology in rats with MBP-induced experimental autoimmune encephalomyelitis. Graefes Arch Clin Exp Ophthalmol 2011; 249(7): 1009-1020.

37 Laspas P, Gramlich OW, Muller HD, Cuny CS, Gottschling PF, Pfeiffer $\mathrm{N}$ et al. Autoreactive antibodies and loss of retinal ganglion cells in rats induced by immunization with ocular antigens. Invest Ophthalmol Vis Sci 2011; 52(12): 8835-8848.

38 Joachim SC, Gramlich OW, Laspas P, Schmid H, Beck S, von Pein $\mathrm{HD}$ et al. Retinal ganglion cell loss is accompanied by antibody depositions and increased levels of microglia after immunization with retinal antigens. PLoS One 2012; 7(7): e40616.

39 Joachim SC, Mondon C, Gramlich OW, Grus FH, Dick HB. Apoptotic retinal ganglion cell death in an autoimmune glaucoma model is accompanied by antibody depositions. J Mol Neurosci 2014; 52(2): 216-224.

40 Noristani R, Kuehn S, Stute G, Reinehr S, Stellbogen M, Dick HB et al. Retinal and Optic Nerve Damage is Associated with Early Glial Responses in an Experimental Autoimmune Glaucoma Model. J Mol Neurosci 2016; 58(4): 470-482.

41 Gramlich OW, Lueckner TC, Kriechbaum M, Teister J, Tao X, von Pein $\mathrm{HD}$ et al. Dynamics, alterations, and consequences of minimally invasive intraocular pressure elevation in rats. Invest Ophthalmol Vis Sci 2014; 55(1): 600-611.

42 Joos KM, Li C, Sappington RM. Morphometric changes in the rat optic nerve following short-term intermittent elevations in intraocular pressure. Invest Ophthalmol Vis Sci 2010; 51(12): 6431-6440.

43 Gramlich OW, Teister J, Neumann M, Tao X, Beck S, von Pein HD et al. Immune response after intermittent minimally invasive intraocular pressure elevations in an experimental animal model of glaucoma. J Neuroinflammation 2016; 13(1): 82.

44 Bell K, Wilding C, Funke S, Pfeiffer N, Grus FH. Protective effect of 14-3-3 antibodies on stressed neuroretinal cells via the mitochondrial apoptosis pathway. BMC Ophthalmol 2015; 15(1): 64

45 Wilding C, Bell K, Beck S, Funke S, Pfeiffer N, Grus FH. Gamma-synuclein antibodies have neuroprotective potential on neuroretinal cells via proteins of the mitochondrial apoptosis pathway. PLoS One 2014; 9(3): e90737.

46 Wilding C, Bell K, Funke S, Beck S, Pfeiffer N, Grus FH. GFAP antibodies show protective effect on oxidatively stressed neuroretinal cells via interaction with ERP57. J Pharmacol Sci 2015; 127(3): 298-304.

47 Bell K, Wilding C, Funke S, Perumal N, Beck S, Wolters D et al. Neuroprotective effects of antibodies on retinal ganglion cells in an adolescent retina organ culture. $J$ Neurochem 2016; 139(2): 256-269.

48 Bringmann A, Pannicke T, Grosche J, Francke M, Wiedemann P, Skatchkov SN et al. Muller cells in the healthy and diseased retina. Prog Retin Eye Res 2006; 25(4): 397-424.

49 Gramlich OW, Beck S, von Thun Und Hohenstein-Blaul N, Boehm N, Ziegler A, Vetter JM et al. Enhanced insight into the autoimmune component of glaucoma: IgG autoantibody accumulation and pro-inflammatory conditions in human glaucomatous retina. PLoS One 2013; 8(2): e57557.

50 Boehm N, Wolters D, Thiel U, Lossbrand U, Wiegel N, Pfeiffer $\mathrm{N}$ et al. New insights into autoantibody profiles from immune privileged sites in the eye: a glaucoma study. Brain Behav Immun 2012; 26(1): 96-102. 